war Theravada Buddhist practice and gender roles, and post-Pol Pot Cambodia are classics. May also contributed to the reemergence of Cambodian studies through her service on the Social Science Research Council's Indochina Studies Committee. She was an active member of the Thailand/Laos/Cambodia Committee of the Association for Asian Studies. Besides her important and meticulous work as an ethnographer and scholar, May was a caring teacher and a generous mentor. She was also a gracious, classy human being. May is survived by her husband, Marvin Gelfand, and her sons, Adam and Jeremy. Buddhist ceremonies were held in Svay Village, Kandal Province, Cambodia, June 10 and 11, 2005.

JUDY LEDGER WOOD

Northern Illinois University

\title{
ELGIN HEINZ
}

(July 25, 1913-April 26, 2005)

We sadly mourn the passing of Elgin Heinz, who died on April 26, 2005, at his home in San Rafael, California, at the age of ninety-one. Although his body had become frail in recent years, Elgin's mind remained as sharp as ever. Those of us who looked forward to his annual winter solstice message reviewing the state of the planet were well aware of this, and we will sorely miss his insight, his wit, and his humanity.

Elgin's was, to say the least, a remarkable life. He was born in 1913 on the campus of Tsinghua University, where his father was one of the original faculty members of the then new institution set among former Qing royal gardens. In his early years, he was as fluent in Chinese as he was in English (much to the chagrin of his relatives when he first visited the United States). After Elgin learned to read, the majority of his early education consisted of reading through the Tsinghua library and leading something of a "Young Indiana Jones" life of curious investigation exploring the Chinese countryside. David Weitzman recalls how Elgin had enchanted us with stories "describing his riding through villages, with his bright red hair, green eyes, and pale, freckled skin meeting and terrifying Chinese farmers who had never seen a white man before, certainly not one who looked like him. He was sure they saw him as the redhaired devil. An interesting image given our memories of the soft spoken, gentle Elgin we knew in his later years."

Elgin entered the University of California, Berkeley, in 1930. Searching for a major in a department that did not compartmentalize knowledge, he chose public speaking because he could take courses across many disciplines using his major to provide framework and form. Again he was to haunt the library, even reporting that he obtained the floor plan from Building and Grounds so that he could navigate its many corridors. Elgin's love affair with books never ended, and he had a remarkable collection, even adding a room to his house to accommodate his ever-expanding library. In 1934 he received his bachelor's degree and later earned a graduate degree in history from San Francisco State University

In the fall of 1935, Elgin started teaching English and public speaking at Balboa High School in San Francisco and subsequently taught geography and history. He spent the next forty years as a teacher in the San Francisco schools, interrupted only 
by occasional excursions to Asia and a year as education director of the Japan Society in 1960. Elgin reported that in his first year of teaching one student told him: "We didn't have the slightest idea of what you were talking about, but it was sure interesting." As Elgin's daughter, Kathy, puts it, "[t] that comment began Elgin's prodigious quest to become a better teacher, a quest he continued for the rest of his life."

To most of us, Elgin is best known for his commitment to bringing Asia to American students. He, along with the late Jackson Bailey and Franklin Buchanan, is known as one of the true pioneers of the movement to improve teaching about Asia. In beginning workshops with teachers, he often began with an anecdote from his own teaching. He was discussing how to fund a trip to Asia with a group of students at Washington High School in San Francisco, where one could literally see the Pacific Ocean from the window. A student asked, "Mr. Heinz, if it's so expensive to fly to Japan, why don't we take a bus?"

Perhaps because he was inspired in part by such incidents, challenging Americans' ignorance about Asia was central to Elgin's life's work, and he became nationally known for it. I first came to know him in the early 1970s when he played a key role in the development of the Bay Area China Education Project, which was the precursor of both the Bay Area Global Education Program (BAGEP) and the Stanford Program on International and Cross-Cultural Education (SPICE). He was a key participant in summer institutes at Stanford and at the Consortium for Teaching Asia and the Pacific in the Schools at the East-West Center of the University of Hawai' $i$, Manoa, on teaching about Asia from the 1980s until recent years. He sometimes accompanied study tours to Asia where the Asian hosts recognized him as a "national treasure," which indeed he was.

Elgin was the recipient of many awards, including the National Geographic Education's California Teacher of the Year, the World Affairs Council of Northern California's Castile Award, and a 1987 award for fifty years of teaching about Asia from the Association for Asian Studies Committee on Teaching About Asia. In 2001 the U.S.-Japan Foundation established the Elgin Heinz Outstanding Teacher Award to recognize exceptional teachers who further mutual understanding between Americans and Japanese. It is presented annually to precollege teachers in two categories: humanities and the Japanese language. Elgin was very honored by the naming of this award and attended the first award ceremony in San Francisco in 2002.

Elgin was an exceptional writer as well as an exceptional speaker, and he authored and edited numerous publications on teaching about Asia, including two widely used curriculum guides, Opening Doors and Stepping Stones. Somewhere in a university archive, you might also find a remarkable 1979 film, Teaching About Japan. Using three demonstration lessons taught by Elgin, this film introduces techniques of teaching about other cultures using Japan as an example. Asked to facilitate the shooting of the movie at Stanford, I remember being doubtful that any film could capture the "teachable moments" of Elgin, but it worked and through it we were able to introduce Elgin to thousands of teachers.

Elgin is survived by his brother, John, his son, Alexander, his daughter, Katherine Jerome, and his granddaughter, Janella Jerome. Elgin's beloved wife of sixty-six years, Doris, passed away in January 2001. Anyone who traveled with him knew that he wrote her elegant and romantic letters daily.

Elgin did not want any formal memorial service, so an informal celebration of his life was held at his home on Saturday, May 2, 2005. Ever the teacher, he donated his body to the UC San Francisco Medical School as a vehicle for student education. The family asks that in lieu of other memorials, contributions be made in Elgin's name 
to Education About Asia, c/o Association for Asian Studies, 1021 E. Huron St., Ann Arbor, MI 46104.

(Special thanks are due to Kathy Jerome, Gary Mukai, David Weitzman, Tuckie Yirchott, and Lucien Ellington for their assistance. Information is also drawn from the fall 2000 issue of Education About Asia (5[2]), and I would refer readers to Elgin's article, "Teaching about Other Cultures," in the same issue.)

DAVID GROSSMAN

Hong Kong Institute of Education

\title{
JARET WEISFOGEL
}

(December 5, 1966-April 25, 2005)

On April 25, 2005, Dr. Jaret Weisfogel died, at the age of thirty-eight, after a four-year battle with cancer. Dr. Weisfogel had received his PhD from the Department of East Asian Languages and Cultures at Columbia University in 2002 and held a Heyman Center postdoctoral fellowship until his illness required him to step down from teaching. His dissertation was entitled "Confucians, the Shih Class, and the Ming Imperium: Uses of Canonical and Dynastic Authority in Kuan Chih-tao's (15361608) Proposals for Following the Men of Former Times to Safeguard Customs (Ts'ung-hsien wei-su i).” Dr. Weisfogel painstakingly read Guan Zhidao's detailed program for ritual in daily practice against both his personal and social context, as well as the classical texts and early Ming proclamations Guan drew on, to illuminate

long-term changes in elite status and identity. A longer obituary, and an article by Dr. Weisfogel that is part of a larger project in which he was a moving spirit, will appear in issue 50 of Ming Studies.

\author{
SARAH SCHNEEWIND \\ Southern Methodist University \\ ROBERT HYMES \\ Columbia University
}

